Acta Agroph., 2019, 26(2), 53-60

doi: $10.31545 /$ aagr/112293

\title{
EFFECT OF PRECIPITATION AND TEMPERATURE CONDITIONS OF CENTRAL EAST POLAND ON FEED VALUE OF EUROPEAN MAIZE CULTIVARS CULTIVATED FOR SILAGE
}

\author{
Barbara Gąsiorowska, Anna Ptaza, Emilia Rzążewska, Michat Waranica \\ Department of Agrotechnology, Faculty of Natural Sciences \\ Siedlce University of Natural Sciences and Humanities \\ ul. Konarskiego 2, 08-110 Siedlce, Poland \\ e-mail: anna.plaza@uph.edu.pl
}

\begin{abstract}
A bstract. The study was conducted in the years 2009-2011, on a private farm. The experiment was set up in the split-plot design, in three replicates. Two experimental factors were analysed: A time of harvest of maize green forage: I - in the stage of tasseling ( $75 \%$ of the plants in that stage of growth), II - in the stage of milky ripeness of the plants (after three weeks), III - in the stage of waxy ripeness of the plants (after three weeks), and B - cultivars with various lengths of the vegetation period: Pyroxenia, Codimi, Moschus, Alombo, Celive. The following parameters were determined in the collected samples of plant material: content of crude ash, digestibility of organic matter, and digestibility of dry matter. The results obtained permit the conclusion that the precipitation and temperature conditions in the years of the study caused a significant differentiation in the feed value of the green forage of the European maize cultivars. The digestibility of organic matter (OM) and the digestibility of dry matter (DM) of maize green forage were the highest if the harvest was performed in the stage of waxy ripeness of the plants in 2010 , a year with the highest precipitation total. The objective of the study was to determine the effect of the harvest date, and of the selection of cultivars from the Common catalogue of varieties of agricultural plant species (CCA), cultivated in relation to the precipitation and temperature conditions, on the feed value of green forage of maize plants.
\end{abstract}

Keyw ord s: maize, cultivars, harvest date, digestibility of organic matter, digestibility of dry matter

\section{INTRODUCTION}

Climatic and agrotechnical factors, including the selection of cultivars, determine the plant structure. The effect of this can be a considerable variation in the chemical composition of maize plants, and of the feed value of maize and of silage prepared from it (Adamczyk 2001, Michalski et al. 2002, Kowalik and Michalski 2009). Maize, as opposed to other plants grown for silage, accumulates nutrients 
until the moment of attaining full ripeness. That trait assumes a greater importance with the appearance of new maize cultivars on the market, including those listed in the Common catalogue of varieties of agricultural plant species (CCA), of the "stay green" type, a characteristic feature of which is the ripening of seeds while the green form of the plants is maintained. The fact that the leaves and stems of the plants stay green for a long time allows delayed harvest, even at the beginning of the stage of full ripeness of seeds (Jha et al. 1998, Hertmann et al. 2000, Kowalik 2001).

The quality of harvested yield of maize green forage is determined in $40 \%$ by agrotechnical factors, in $30 \%$ by climatic factors, and in $30 \%$ by the selection of cultivars (Ptaszyńska and Sulewska 2008, Lynch et al. 2012, Magalhäes et al. 2015). The weather conditions during the period of vegetation have a strong impact on the yield and on the feed value of maize plants. An excess, but also a deficit of precipitation, and too low or too high air temperature, largely determine the quality of the harvested green forage (Hopkins 2003). Climate warming has both a direct and an indirect impact on certain weather parameters, e.g. on the amount and distribution of precipitations, on the occurrence of drought and dry spells (Farre and Faci 2006, Sulewska et al. 2011). And therefore it is necessary to conduct research on the cultivation of maize in variable weather conditions, especially as new maize cultivars appear on the market.

The objective of the study was to determine the effect of the harvest date, and of the selection of cultivars from the Common catalogue of varieties of agricultural plant species (CCA), cultivated in relation to the precipitation and temperature conditions, on the feed value of green forage of maize plants.

\section{MATERIAL AND METHOD}

The field experiment was conducted in the years 2009-2011, in a private farm situated in the locality of Kowiesy near Siedlce $\left(52^{\circ} 03^{\prime} 39^{\prime \prime} \mathrm{N}, 22^{\circ} 33^{\prime} 80^{\prime \prime} \mathrm{E}\right)$. The field experiment was conducted on a grey-brown podzolic soil, sandified, with a slightly acidic reaction and with a medium content of available phosphorus, potassium and magnesium. The content of humus was $1.28 \%$. The experiment was set up in the split-lot design, in three replicates. Two experimental factors were analysed: A - harvest date of green forage of maize (I - in the stage of tasseling $(75 \%$ of the plants in that stage) BBCH 51, II - in the stage of milky ripeness (after three weeks) $\mathrm{BBCH} 73$, III - in the stage of waxy ripeness (after another three weeks) $\mathrm{BBCH}$ 85), and $\mathrm{B}$ - cultivars with various lengths of the period of vegetation: (Pyroxenia- very early FAO 130, Codimi - early FAO 200, Moschus - early FAO 220, Alombo - medium early FAO 230, Celive - medium early FAO 245). 
The plant density was 10 plants per $\mathrm{m}^{-2}$, and the applied sowing standard was determined by the results obtained in an earlier study by Sulewska (2001). FYM was applied in the autumn, at the dose of $30 \mathrm{tha}^{-1}$. In spring, phosphorus-potassium fertilisation was applied, in doses adapted to the soil levels of available components, i.e. $60 \mathrm{~kg} \mathrm{P} \mathrm{ha}^{-1}$ and $90 \mathrm{~kg} \mathrm{~K} \mathrm{ha}^{-1}$. Nitrogen fertilisation was also applied in spring, prior to the sowing of maize, at the dose of $92 \mathrm{~kg} \mathrm{~N} \mathrm{ha}^{-1}$, and the extra dose of nitrogen was supplemented by the application of mineral fertilisation in the form of Polifoska 6. Seeds of the analysed cultivars were sown in the $3^{\text {rd }}$ decade of April, in accordance with the second experimental factor. The harvest of plants for green matter was conducted on three dates, in accordance with the first experimental factor. During the harvest, samples of plant material were collected from every plot, for the determination of the following parameters: content of crude ash, digestibility of organic matter and digestibility of dry matter, with the method of near-infrared spectroscopy (NIRS) using the NIRFex N-500 apparatus.

The results obtained were processed statistically, and for each of the analysed parameters analysis of variance was performed, suitable for a two-factor experiment set up in the split-plot design. For detailed comparison of mean values, the least significant differences LSD were calculated on the basis of Tukey's test, at significance level $\alpha_{0.05}$.

Table 1. Temperature and precipitation conditions during the vegetation of maize plants according to the Meteorological Station at the Agricultural Experimental Station Zawady

\begin{tabular}{|c|c|c|c|c|c|c|c|}
\hline \multirow{2}{*}{ Year } & \multicolumn{6}{|c|}{ Month } & \multirow[t]{2}{*}{ Mean / total } \\
\hline & IV & $\mathrm{V}$ & VI & VII & VIII & IX & \\
\hline \multicolumn{8}{|c|}{ Air temperature,${ }^{\circ} \mathrm{C}$} \\
\hline 2009 & 10.3 & 12.9 & 15.7 & 19.4 & 17.7 & 14.6 & 15.1 \\
\hline 2010 & 8.9 & 14.0 & 17.4 & 21.6 & 19.8 & 11.8 & 15.6 \\
\hline 2011 & 10.1 & 13.4 & 18.1 & 18.3 & 18.0 & 14.4 & 15.4 \\
\hline Multi-year average & 8.3 & 14.1 & 17.5 & 19.8 & 18.9 & 13.1 & 15.3 \\
\hline 1990-2008 & & & & & & & \\
\hline \multicolumn{8}{|c|}{ Precipitation total, $\mathrm{mm}$} \\
\hline 2009 & 8.1 & 68.9 & 145.2 & 26.4 & 80.9 & 24.9 & 354.4 \\
\hline 2010 & 10.7 & 93.2 & 62.6 & 77.0 & 106.3 & 109.9 & 459.7 \\
\hline 2011 & 31.0 & 36.1 & 39.1 & 120.2 & 18.6 & 12.0 & 257.0 \\
\hline $\begin{array}{l}\text { Multi-year average } \\
1990-2008\end{array}$ & 35.6 & 49.3 & 47.5 & 63.4 & 54.2 & 47.8 & 297.8 \\
\hline
\end{tabular}

The temperature and precipitation conditions in the years of the study are presented in Table 1. The year 2010 was characterised by the highest mean air temperature and the highest precipitation total. The maize plant displays the highest demand for water in the flowering stage, i.e. from the middle of July to the middle of August. In 2010, the precipitation total for those months was $120.2 \mathrm{~mm}$ and $106.3 \mathrm{~m}$, respectively. This had a favourable effect on the yielding of maize. In 2009 the precipitation total 
was lower, though still higher than the average multi-year total. However, in August the precipitation total was $80.9 \mathrm{~mm}$ and it was higher than the average multi-year total, which had a positive impact on maize plants. Whereas, in 2011 the lowest precipitation total was noted, below the average multi-year total, and the mean air temperature oscillated around the mean multi-year temperature. Although in 2011 the lowest precipitation total was noted, the total in July was $120.2 \mathrm{~mm}$, i.e. twice as much as the average multi-year precipitation total, which had a beneficial effect on maize plants.

\section{RESULTS AND DISCUSSION}

The content of crude ash in maize plants was significantly differentiated by the weather conditions during the period of vegetation, and by their interactions with the analysed factors (Tab. 2). The highest content of crude ash was noted in maize plants harvested in 2009, a significantly lower content in plants harvested in 2011, and the lowest in 2010, the year with the highest precipitation total. Also studies by Hopkins (2003) and by Ferre and Faci (2006) indicate a differentiation in the chemical composition of maize plants cultivated in variable weather conditions. Our study demonstrated an interaction of weather conditions with the experimental factors. The highest content of crude ash was characteristic of green matter of all of the analysed maize cultivars harvested in 2009 in the stage of tasseling. A significantly lower content of crude ash was noted in plants of all maize cultivars harvested in the stage of milky ripeness in 2010, and the lowest in plants of all maize cultivars harvested in the stage of waxy ripeness, also in 2010, the year with the highest

Table 2. Content of crude ash in dry matter of maize plants $\left(\mathrm{g} \mathrm{kg}^{-1}\right)$

\begin{tabular}{llccc}
\hline \multirow{2}{*}{ Harvest date } & \multirow{2}{*}{ Cultivar } & \multicolumn{3}{c}{ Year } \\
\cline { 3 - 5 } I & Pyroxenia & 2009 & 2010 & 2011 \\
\cline { 3 - 5 } & Codimi & 81.1 & 70.5 & 92.3 \\
& Moschus & 87.8 & 71.3 & 73.6 \\
& Alombo & 85.1 & 73.3 & 82.6 \\
II & Celive & 84.5 & 74.8 & 91.0 \\
& Pyroxenia & 58.9 & 75.8 & 79.3 \\
& Codimi & 58.0 & 38.5 & 57.2 \\
& Moschus & 65.2 & 51.7 & 59.6 \\
& Alombo & 70.1 & 51.6 & 62.8 \\
III & Celive & 67.2 & 56.0 & 60.8 \\
& Pyroxenia & 68.0 & 51.7 & 61.7 \\
& Codimi & 47.2 & 33.5 & 35.8 \\
& Moschus & 47.8 & 30.7 & 41.2 \\
& Alombo & 54.7 & 38.4 & 45.4 \\
& Celive & 55.7 & 32.2 & 39.2 \\
Mean & & 57.1 & 36.4 & 43.5 \\
\hline
\end{tabular}

LSD 0.05; Years $=3$; Interaction: years $\times$ harvest date $\times$ cultivar $=10.00$. 
precipitation total. Also Filya (2004), Stejskalova et al. (2013) and Komainda et al. (2018) demonstrated that, irrespective of the weather conditions, postponement of maize plants harvest from the stage of early milky ripeness to the stage of waxy ripeness caused a decrease in the content of crude ash. In the experiment presented here, plants of all maize cultivars harvested in the stage of tasseling in 2009 had the highest content of crude ash. This is conformance with the results of studies conducted by Tolera et al. (1999), Sulewska (2001), Yuxiang et al. (2007), Schttenhelm (2008), and by Podkówka et al. (2015), who demonstrated that all cultivars were characterised by a high concentration of crude ash when cultivated in years with a favourable distribution of precipitations and air temperatures. In our study, the highest content of crude ash was characteristic of cultivars Pyroxenia, Moschus and Alombo, harvested in 2011, a year with a favourable distribution of weather conditions, in the stage of tasseling.

Statistical analysis revealed a significant effect of the precipitation and temperature conditions during vegetation, of maize cultivars, and their interactions with the experimental factors, on the digestibility of organic matter (Tab. 3). The highest level of digestibility of organic matter (OM) was noted for maize plants harvested in the wet year 2010, and significantly lower in the years 2009 and 2011. The quality of harvested yield of green matter of maize is determined in $30 \%$ by the weather conditions (Ptaszyńska and Sulewska 2008). Plants cultivated in years with a high amount of precipitations are characterised by a lower content of crude fibre and its fractions, with ensures better digestibility of organic matter of maize. Our study demonstrated an interaction which shows that the highest level of digestibility of organic matter

Table 3. Digestibility of organic matter of maize plants (OM)

\begin{tabular}{lllll}
\hline \multirow{2}{*}{ Harvest date } & \multicolumn{1}{c}{ Cultivar } & 2009 & 2010 & 2011 \\
\cline { 3 - 5 } I & Pyroxenia & 54.04 & 58.56 & 48.27 \\
& Codimi & 51.60 & 56.45 & 53.23 \\
& Moschus & 51.91 & 55.89 & 50.92 \\
& Alombo & 50.87 & 56.80 & 49.18 \\
& Celive & 50.38 & 57.31 & 53.96 \\
II & Pyroxenia & 64.02 & 75.86 & 59.59 \\
& Codimi & 62.08 & 69.21 & 58.59 \\
& Moschus & 59.32 & 69.39 & 57.96 \\
& Alombo & 57.79 & 67.49 & 58.59 \\
& Celive & 56.86 & 69.42 & 59.34 \\
III & Pyroxenia & 68.63 & 76.97 & 69.35 \\
& Codimi & 67.03 & 77.32 & 68.69 \\
& Moschus & 65.51 & 74.89 & 68.54 \\
& Alombo & 65.03 & 77.69 & 66.92 \\
& Celive & 66.33 & 76.60 & 68.10 \\
Mean & & 59.43 & 67.99 & 59.42 \\
\hline
\end{tabular}

LSD 0.05; Years $=1.41$; Interaction: years $\times$ harvest date $\times$ cultivar $=4.72$. 
(OM) was characteristic of cultivar Pyroxenia harvested in the stage of milky ripeness in 2010, and of all maize cultivars harvested in the stage of waxy ripeness in 2010, and the lowest - of all maize cultivars harvested in the stage of tasseling in the years 2009 and 2011. This is convergent with the results of studies by Michalski et al. (2002), Sulewska (2001), Filya (2004), and by Swanckaert et al. (2016).

Table 4. Digestibility of dry matter of maize plants (DM), \%

\begin{tabular}{lllll}
\hline \multirow{2}{*}{ Harvest date } & \multicolumn{1}{c}{ Cultivar } & 2009 & 2010 & 2011 \\
\cline { 3 - 5 } I & Pyroxenia & 54.53 & 55.89 & 48.02 \\
& Codimi & 52.82 & 54.14 & 53.44 \\
& Moschus & 52.80 & 53.67 & 51.15 \\
& Alombo & 51.53 & 54.56 & 49.02 \\
& Celive & 50.94 & 55.29 & 53.75 \\
II & Pyroxenia & 62.95 & 72.72 & 59.59 \\
& Codimi & 61.09 & 65.82 & 58.59 \\
& Moschus & 58.05 & 65.86 & 57.96 \\
& Alombo & 56.89 & 63.96 & 58.59 \\
& Celive & 56.44 & 66.17 & 59.34 \\
III & Pyroxenia & 67.29 & 73.54 & 69.35 \\
& Codimi & 65.93 & 73.94 & 68.69 \\
& Moschus & 64.29 & 71.01 & 68.54 \\
& Alombo & 63.60 & 73.80 & 66.93 \\
& Celive & 65.52 & 73.26 & 68.10 \\
Mean & & 58.98 & 64.91 & 59.40 \\
\hline
\end{tabular}

LSD 0.05; Years $=1.38$; Interaction: years $\times$ harvest date $\times$ cultivar $=4.56$.

Digestibility of dry matter of maize plants (DM) was significantly differentiated by the weather conditions and their interactions with the experimental factors (Tab. 4). The highest level of digestibility of dry matter was characteristic of maize plants harvested in 2010, the year with the highest precipitation total, and significantly lower of plants harvested in the years 2009 and 2011. This should be attributed to the fact that maize plants cultivated in years with high precipitation totals contain less crude fibre and its fractions, which enhances the digestibility of dry matter (Hopkins 2003, Ptaszyńska and Sulewska 2008). The study demonstrated an interaction which shows that the highest digestibility of dry matter (DM) was characteristic of all maize cultivars harvested in the stage of waxy ripeness in 2010, and of cultivar Pyroxenia harvested in 2011, while the lowest level of dry matter digestibility was characteristic of cultivars Alombo and Celive harvested in the stage of tasseling in 2009, and of cultivars Pyroxenia, Moschus and Alombo, also harvested in the stage of tasseling, but in 2011. A similar relationship was noted by Michalski et al. (2002) and by Swanckaert et al. (2016). 


\section{CONCLUSIONS}

1. The temperature and precipitation conditions in the years of the study significantly differentiated the feed value of green forage of the European maize cultivars.

2. The highest content of crude ash was characteristic of green forage of maize cultivars Pyroxenia, Moschus and Alombo harvested in the stage of tasseling in 2011.

3. The digestibility of organic matter (OM) and the digestibility of dry matter (DM) of maize green forage were the highest if the harvest of all of the analysed cultivars was performed in the stage of waxy maturity in 2010, the year with the highest precipitation total, and of cultivar Pyroxenia harvested in the stage of milky ripeness.

4. Irrespective of the year of the study and the harvest date, green forage of maize cultivar Pyroxenia was characterised by the best quality.

\section{REFERENCES}

Adamczyk J., 2001. The importance of selecting varieties in the cultivation of maize for grain and silage (in Polish). Biul. Inf. IŻ-R., XXXIX, 1, 29-35.

Farre I., Faci J.M., 2006. Comparative response of maize (Zea mays L.) and sorghum (Sorghum bicolor L. Moench) to deficit irrigation in a Mediterranean environment. Agric. Water Manag., 8(3), 135-143, https://doi.org/10.1016/j.agwat.2005.11.001

Filya I., 2004. Nutritive value and aerobic stability of whole crop maize silage harvested at four stages of maturity. Anim. Feed Sci. Tech., 116, 141-150, https://doi.org/10.1016/j.anifeedsci.2004.06.003

Hertmann A., Presterl T., Gedger H., 2000. Bestimmung des optimalen Erntezeitpunktes von Silomaissorten mit langsamer versus Schneller Restpflanzenabreife. Landbauforsch. Völkenrode Sonderh, 217 In: Tagungsband "Zum Futterwert von Mais" (Eds. P. Lebzien, F.J. Schwarz, J. Rath). 86-93.

Hopkins A., 2003. Potential impacts of climate change for grassland: farming industry perceptions, adaptations and mitigation options. Grass. Sci. in Eur., 8, 483-486.

Jha P.B., Ghosh J., Nirala R.B.P., 1998. Genetic variability and character association in fodder maize. J. Res. Birsa Agric. Univ., 10(2), 139-143.

Komainda M., Taube F., Klub Ch., Antje H., 2018. The effects of maize (Zea Mays L.) hybrid and harvest date on above- and belowground biomass dynamics, forage yield and quality - A tradeoff for carbon inputs?. Eur. Jour. Agron., 92, 51-62, https://doi.org/10.1016/j.eja.2017.10.003

Kowalik I., 2001. Variability and correlation of elements of the maize yield structure (Zea mays L.) depending on weather conditions and nitrogen fertilization (in Polish). Rocz. AR Poznań, Rol., 61, 77-87.

Kowalik I., Michalski T., 2009. Content of dry matter in raw material as an estimated indicator of feed value of silage of maize (in Polish). Nauk. Przyr. Tech., 3(2),1-10.

Lynch J.P., O'Kiely P., Doyle E.M., 2012. Yield, quality and ensilage characteristics of whole-crop maize and of the cob and stover components: harvest date and hybrid effect. Grass Forage Sci., 67(4), 472-487, https://doi.org/10.1111/j.1365-2494.2012.00868.x

Magalhäes A., Rolim M., Duarte A., Pedrosa E., Silva E., 2015. Chemical attributes of soil and dry mass accumulation of maize fertilized with cassava wastewater. Engen. Agric., 35(3), 458-469, https://doi.org/10.1590/1809-4430-Eng.Agric.v35n3p458-469/2015

Michalski T., Kruczyńska H., Kowalik I. 2002. Yields and quality of ensilaging maize depending on the cultivar and mowing height at harvest. Acta Sci. Pol. Agric., 1(2), 83-92. 
Podkówka L., Podkówka Z., Piwczyński D., Buko M., 2015. The influence of varietal earliness on the chemical composition and digestibility of maize grain (in Polish). Rocz. Nauk Zoot., 42(2), 155-169.

Ptaszyńska G., Sulewska H., 2008. Variability of yielding of hybrids of maize of various earliness in climatic conditions of central Wielkopolska (in Polish). Acta Sci. Pol. Agric., 7(3), 93-103.

Schttenhelm S., 2008. Chemical composition and methane field of maize hybrids with contrasting maturity. Eur. Jour. Agron., 29(2-3), 72-78, https://doi.org/10.1016/j.eja.2008.04.001

Stejskalova M., Hejcmanova P., Hejcman M., 2013. Forage value of leaf fodder of main European broad-leaved woody species. The role of grassland in a green future. Grassl. Sci. Europe., 18, 85-87.

Sulewska H., Adamczyk J., Rejek D., 2011. Evaluation of the yield of new hybrids of fodder maize (Zea Mays L.) of Smolice Breeding. Nauka Przyr. Tech., 5(1), 1-11.

Sulewska H., 2001. Yielding and nutritive value of maize harvested on green mass depending on some agrotechnical factors (in Polish). Rocz. AR Poznań. Rozp. Nauk., 315.

Swanckaert J., Pannecoucque J., Van Waes J., Cauwer B., Latre J., Haesaert G., Reheul D., 2017. Harvest date does not influence variety ranking in Belgian forage maize variety trials. Jour. Agric. Sci., 154(6), 1040-1050, https://doi.org/10.1017/S0021859615000994

Tolera A., Berg T., Sundstolb F., 1999. The effect of variety on maize grain and crop residue yield and nutritive value of the stover. Anim. Feed Sci. Tech., 79(3), 165-177, https://doi.org/10.1016/ S0377-8401(99)00025-5

Yuxiang, Ch., Jing, Ch., Daowei Z., 2007. Effect of harvest date on shearing force of maize stems. In Liv. Sci., 111(1), 33-44, https://doi.org/10.1016/j.livsci.2006.11.013 